\title{
Efficacy and safety of aerosol inhalation of recombinant human interferon $a 1 b$ (IFNa1b) injection for noninfluenza viral pneumonia, a multicenter, randomized, double-blind, placebo-controlled trial
}

Rongmeng Jiang ${ }^{1}$, Bing Han ${ }^{1}$, Meihua Song ${ }^{1}$, Bing Xue ${ }^{2}$, Yongxiang Zhang ${ }^{3}$, Yanyan Ding ${ }^{3}$, Jin Chen ${ }^{4}$, Jing Zhu ${ }^{4}$, Jianhua Liư ${ }^{5}$, Qingrong Nie ${ }^{6}$, Xuefeng Han ${ }^{6}$, Xiuhong Jin ${ }^{7}$, Xiaoyin Shan ${ }^{7}$, Weian Guo ${ }^{8}$, Erming Zhang ${ }^{8}$, Zuoqing Zhang ${ }^{9}$, Changhong Zhang ${ }^{9}$, Jie Zhang ${ }^{10}$, Baozeng Wang ${ }^{11}$, Shuwen Dong ${ }^{10}$, Jiandong $\mathrm{Li}^{12}$, Xiaoguang $\mathrm{Li}^{13}$ and Xingwang $\mathrm{Li}^{\mathrm{i}^{*}}$

\begin{abstract}
Background: To investigate the efficacy and safety of aerosol inhalation of recombinant human interferon a1b (IFNa1b) injection for noninfluenza viral pneumonia.

Methods: One hundred sixty-four patients with noninfluenza viral pneumonia were divided into IFNa1b and control groups. The IFNa1b group received routine treatment + aerosol inhalation of recombinant human IFNa1b injection $(50 \mu \mathrm{g} \times 2$ injections, bid). The control group received routine treatment + IFN analog (two injections, bid). Overall response rate (ORR) of five kinds clinical symptoms. Further outcomes were daily average score and the response rate of each of the symptoms above.

Results: A total of 163 patients were included in the full analysis set (FAS) and 151 patients were included in the per-protocol set (PPS). After 7 days of treatment, ORR of clinical symptoms was higher in IFNa1b group than that in control group for both the FAS and PPS. Moreover, after 7 days of treatment, the daily score of three efficacy indexes including expectoration, respiratory rate, and pulmonary rales were improved. The ORRs for expectoration and pulmonary rales were higher in the IFNa1b group than in the control group $(P<0.05)$. There were no significant differences of the ORRs for coughing, chest pain and respiratory rate between the two groups $(P>0.05)$. The incidence of adverse events was 6.5\% $(n=5)$ in IFNa1 b group and 3.5\% $(n=3)$ in control group $(P>0.05)$.
\end{abstract}

Conclusion: Aerosol inhalation of recombinant human IFNa1b is safe and it can improve the clinical symptoms of noninfluenza viral pneumonia.

Keywords: Noninfluenza viral pneumonia, Recombinant human interferon a1b, Aerosol inhalation, Clinical trial

\footnotetext{
*Correspondence: jiangrm12@163.com

'Department of Infectious Disease, Beijing Ditan Hospital, Capital Medical

University, No. 8 East Jingshun Street, Chaoyang District, Beijing 100015,

China

Full list of author information is available at the end of the article
}

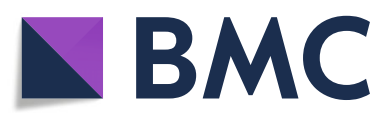

( ) The Author(s). 2020 Open Access This article is licensed under a Creative Commons Attribution 4.0 International License, which permits use, sharing, adaptation, distribution and reproduction in any medium or format, as long as you give appropriate credit to the original author(s) and the source, provide a link to the Creative Commons licence, and indicate if changes were made. The images or other third party material in this article are included in the article's Creative Commons licence, unless indicated otherwise in a credit line to the material. If material is not included in the article's Creative Commons licence and your intended use is not permitted by statutory regulation or exceeds the permitted use, you will need to obtain permission directly from the copyright holder. To view a copy of this licence, visit http://creativecommons.org/licenses/by/4.0/. The Creative Commons Public Domain Dedication waiver (http://creativecommons.org/publicdomain/zero/1.0/) applies to the data made available in this article, unless otherwise stated in a credit line to the data. 


\section{Introduction}

Pneumonia is the leading cause of death in children in developing countries and the elderly in developed countries. Among the pathogens which cause communityacquired pneumonia (CAP), viral pneumonia is attracting increasing attention. It occurs in approximately 200 million people each year worldwide, while adults and children each accounting for $50 \%$ of cases [1]. In recent years, with the development of molecular assays, respiratory viruses have become the leading CAP pathogens [2]. CAP is the most common infectious disease in the United States and the eighth cause of death [3]. It is reported that the economic burden of CAP in the United States alone was estimated to exceed $\$ 17$ billion per year [4]. A CAP study in the United States found that the three most common adult pneumonia pathogens were rhinovirus, influenza virus, and Streptococcus pneumoniae. Other pathogens include human metapneumovirus, respiratory syncytial virus, parainfluenza virus, coronavirus, and adenovirus [2]. Common viruses include influenza virus (8\%), rhinovirus (5.7\%), respiratory syncytial virus (2.2\%), and coronavirus (3.3\%) [5]. In recent years, the mortality of newly developed avian influenza viruses (H7N9, H5N6) and the Middle East respiratory syndrome coronavirus (MERS-CoV) was high. Once $48 \mathrm{~h}$ passed the infection, neuraminidase inhibitors were ineffective for influenza virus infections. Currently, no proved effective antiviral treatment is available to treat and prevent MERS. MERS-CoV is highly homologous to severe acute respiratory syndrome (SARS), therefore, the experience gained from SARS treatment, including the use of IFN $\alpha$, may be helpful in the treatment of MERS$\mathrm{CoV}$ infection. Through in vitro studies, it was found that MERS-CoV was 50 to 100 times more sensitive to IFN $\alpha$ than SARS virus. Therefore, IFN $\alpha$ might be an effective treatment for MERS [6]. IFN $\alpha$ was shown to be effective in patients with chronic active Epstein-Barr virus disease [7, 8]. Sakai et al. reported the application of IFN $\alpha$ to patients with chronic active Epstein-Barr virus disease resulting in unremarkable suppression of lymphocyte proliferation [8]. An open-label trial of systemic IFN improved 28-day survival in patients with ARDS [9].

Interferons (IFNs) are a family of multifunctional cytokines with broad-spectrum antiviral, antiproliferative, and immunomodulatory activities. IFN has broadspectrum antiviral and immunomodulatory effects and is classified as type I, type II or type III based on different binding receptors [10]. Among them, type I IFN (mainly IIB IFN) plays an important role in the control of viral infections. IFN $\alpha$ establishes an antiviral state by inducing cells to produce antiviral proteins, which prevents viral infection [11]. Aerosol inhalation is one route way for IFN administration, which could not only improve efficacy but also reduce the IFN blood concentration in normal tissues, thereby reducing adverse reactions [12]. In clinical practice, IFN $\alpha$ has been widely used to treat various viral diseases in children in some disease [13, 14], but few studies have been conducted to investigate its effect in the treatment of viral pneumonia in adults. Moreover, there were also no consensus on how to use IFN $\alpha$ in adults with viral pneumonia.

Therefore, we performed a multicenter, randomized controlled study to investigate the efficacy and safety of aerosol inhalation of recombinant human IFN $1 \mathrm{~b}$ for noninfluenza viral pneumonia and to provide a basis for its rational use and dose in clinical practice.

\section{Methods}

\section{Study design}

This is a multicenter, randomized, double-blind, placebocontrolled trial, which was approved by the Ethics Committee of Beijing Ditan Hospital Capital Medical University. Each subject was informed of the purpose of the study and potential benefits and risks and signed an informed consent before the study. Inclusion Criteria: The inclusion criteria were as follows: 1) men or women at least 14 years old with pneumonia diagnosed according to the Guidelines for the Diagnosis and Treatment of Adults with Community-Acquired Pneumonia from the Respiratory Disease Branch of the Chinese Medical Association (2016); 2) clinical diagnosis of viral pneumonia; 3) negative tests for influenza viruses; 4) inpatients, within 5 days of onset; and 5) ability to receive aerosol inhalation.

The exclusion criteria were as follows: 1) unequivocal evidence of Tuberculosis bacillus, Streptococcus pneumoniae, Legionella pneumoniae, Mycoplasma pneumoniae, or Chlamydia infection; 2) unequivocal evidence of bacterial infection, procalcitonin $(\mathrm{PCT})>1 \mu \mathrm{g} / \mathrm{L} ; 3)$ use of antiviral drugs in the week before screening or potential need for another antiviral treatment during the study; 4) subjects who required mechanical ventilation; 5) unstable or active chronic lung disease, diabetes, tumor, or HIV infection; 6) severe liver or kidney dysfunction; 7) participating or participated in another clinical study during the 30 days before study treatment; 8 ) a history of IFN allergy or other IFN contraindications; 9) pregnant (positive urine or serum pregnancy test) or nursing women.

\section{Intervention}

The patients were randomly divided into IFN 1 1b group and control group.

The IFN 1 1b group was given routine treatment (antibiotics and antitussive and expectorant drugs) and aerosol inhalation of recombinant human IFNa1b injection (Beijing Tri-Prime Gene Pharmaceutical Co., Ltd., lot\#: 20151206), $50 \mu \mathrm{g} \times 2$ injections, bid. The control group 
was given routine treatment and aerosol inhalation of IFN analog (Beijing Tri-Prime Gene Pharmaceutical Co., Ltd.), 2 injections, bid. Standardized compressor nebulizers were used at all sites to administer treatment via the same nebulization process.

\section{Primary outcome}

The primary outcome was the overall response rate (ORR) of five pneumonia-related symptoms, including coughing, expectoration, chest pain, pulmonary rales, and respiratory rate after treatment. The ORR of clinical symptoms $(\%)=$ (pretreatment score of clinical symptoms - the score of clinical symptoms after 7 days of treatment) / pretreatment score $\times 100 \%$. The clinical signs and symptoms were scored according to the Guiding Principles for Clinical Study of New Chinese Medicines, 0, no coughing, expectoration, chest pain, or
Table 1 Baseline characteristics of the IFNa1b group and the control group (FAS)

\begin{tabular}{lllll}
\hline & & IFNa1b Group & Control Group & $P$ \\
& & 76 & 87 & \\
\hline Sex & Female & $21(27.6 \%)$ & $47(54.0 \%)$ & 0.001 \\
& Male & $55(72.4 \%)$ & $40(46.0 \%)$ & \\
Age & & $55.230 \pm 18.950$ & $51.860 \pm 19.528$ & 0.268 \\
BMl & $24.306 \pm 3.034$ & $23.814 \pm 3.179$ & 0.380 \\
Time of onset (days) & $5.3 \pm 4.2$ & $4.7 \pm 2.7$ & 0.239 \\
\hline
\end{tabular}

pulmonary rales, and a normal respiratory rate; 1 , mild; 2 , severe.

\section{Secondary outcomes}

The secondary efficacy measures were daily average score and the response rate of each of the five pneumonia-related symptoms, including coughing,

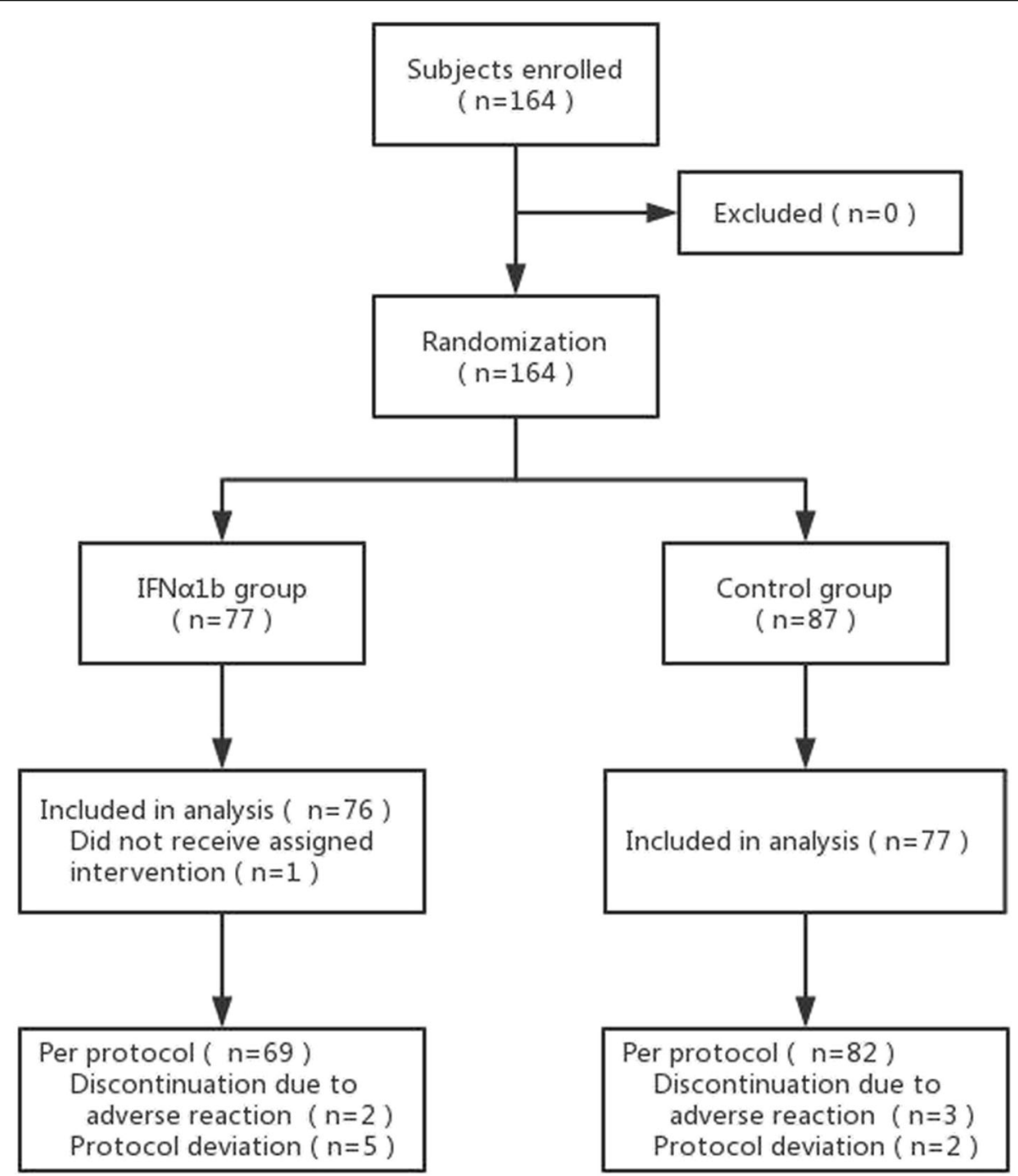

Fig. 1 Flow chart of this study 
Table 2 Pathogen Identification

\begin{tabular}{|c|c|c|c|}
\hline Item & Total & IFNa1b Group & Control Group \\
\hline Influenza virus ${ }^{a}$ & $16(9.94 \%)$ & $9(11.84 \%)$ & $7(8.24 \%)$ \\
\hline Parainfluenza virus & $4(2.48 \%)$ & $3(3.95 \%)$ & $1(1.18 \%)$ \\
\hline Respiratory syncytial virus & $7(4.35 \%)$ & $2(2.63 \%)$ & $5(5.88 \%)$ \\
\hline Rhinovirus & $7(4.35 \%)$ & $3(3.95 \%)$ & $4(4.71 \%)$ \\
\hline Adenovirus & $7(4.35 \%)$ & $5(6.58 \%)$ & $2(2.35 \%)$ \\
\hline EB virus & $16(9.94 \%)$ & $7(9.21 \%)$ & $9(10.59 \%)$ \\
\hline Herpes virus & $14(8.64 \%)$ & $8(10.53 \%)$ & $6(7.06 \%)$ \\
\hline Coronavirus & $2(1.24 \%)$ & $1(1.32 \%)$ & $1(1.18 \%)$ \\
\hline Human metapneumovirus & $1(0.62 \%)$ & $0(0.00 \%)$ & $1(1.18 \%)$ \\
\hline Streptococcus pneumoniae & $2(1.24 \%)$ & $2(2.63 \%)$ & $0(0.00 \%)$ \\
\hline Mycoplasma & $10(6.21 \%)$ & $4(5.26 \%)$ & $6(7.06 \%)$ \\
\hline Chlamydia & $2(1.24 \%)$ & $1(1.32 \%)$ & $1(1.18 \%)$ \\
\hline Moraxella catarrhalis & $2(1.24 \%)$ & $0(0.00 \%)$ & $2(2.35 \%)$ \\
\hline Simple virus infection & $49(30.43 \%)$ & $21(27.63 \%)$ & $28(32.94 \%)$ \\
\hline Single virus infection & $30(18.63 \%)$ & 9 (11.84\%) & $21(24.71 \%)$ \\
\hline Two-virus infection & $9(5.59 \%)$ & $7(9.21 \%)$ & $2(2.35 \%)$ \\
\hline Multivirus infection & $10(6.21 \%)$ & $5(6.58 \%)$ & $5(5.88 \%)$ \\
\hline Mycoplasma + virus & $5(3.11 \%)$ & $2(2.63 \%)$ & $3(3.53 \%)$ \\
\hline Chlamydia + virus & $2(1.24 \%)$ & $1(1.32 \%)$ & $1(1.18 \%)$ \\
\hline
\end{tabular}

${ }^{\text {a }}$ represents negative results from a rapid influenza antigen test during screening and positive results from an influenza virus nucleic acid test at the central laboratory. No anti-influenza drugs were given during clinical treatment.

expectoration, chest pain, pulmonary rales, and respiratory rate before and after treatment.

\section{Safety measures}

The measured vital signs included pulse, blood pressure, body temperature, and respiratory rate. The items of physical examination included skin and mucous membranes, lymph nodes, head and neck, chest, abdomen, spine, musculoskeletal system, nervous system. The clinical laboratory tests included complete blood count and serum biochemical examination.

\section{Statistical analysis}

SAS v9.3 was used for statistical analysis. A two-side $p$ value less than 0.05 was considered to be statistically significant. The full analysis set (FAS) was used to analyze primary outcome, and the per-protocol set (PPS) was

Table 3 ORRs of clinical symptoms in the IFNa1b group and the control group after days of treatment (\%)

\begin{tabular}{lllll}
\hline Group & FAS & ORR & PPS & ORR \\
& $n$ & & $n$ & \\
\hline Control group & 87 & $65.51 \pm 35.59$ & 82 & $66.26 \pm 35.65$ \\
IFNa1b group & 76 & $76.87 \pm 25.15$ & 69 & $77.16 \pm 24.19$ \\
P & 0.037 & & 0.033 & \\
\hline
\end{tabular}

Table 4 Covariance analysis of ORRs of clinical symptoms between the IFNa1b group and the control group after 7 days of treatment

\begin{tabular}{lllll}
\hline & FAS & $P$ & PPS & $P$ \\
& Statistics F & & Statistics F & \\
\hline Covariate effect & 0.557 & 0.457 & 0.317 & 0.574 \\
Sex comparison & 0.929 & 0.337 & 1.493 & 0.224 \\
Between-group comparison & 4.781 & 0.030 & 3.649 & 0.048 \\
Sex and Group & 0.006 & 0.941 & 0.043 & 0.836 \\
\hline
\end{tabular}

used to analyze secondary outcomes. Moreover, a superiority test was performed to analyze primary efficacy measures. Fisher's exact test was used to analyze the overall incidence of adverse events and the incidence of drug-related adverse events.

\section{Results}

\section{General information}

A total of 164 subjects were enrolled in this study. Among them, 163 were included in the FAS, while there were 76 patients in the IFN 1 1b group and 87 patients in the control group. A total of 151 were included in the PPS, there were 69 patients in the IFN $\alpha 1 b$ group and 82 patients in the control group. There were no significant differences of age, body mass index (BMI), or time of onset between the two groups $(P>0.05)$. However, there were significant differences of gender composition between the two groups $(P<0.05)$ (Table 1$)$. During subject screening and enrollment, no significant difference was observed in body temperature, respiratory rate, heart rate, pulse, blood pressure, or blood oxygen saturation level $(\mathrm{P}>0.05)$. No subject was transferred to the RICU due to worsening condition and no subject developed secondary bacterial pneumonia after enrollment during the study. The flow chart of subject screening and enrollment is shown in Fig. 1.

\section{Viral pathogens}

Identified Viral pathogens in the enrolled subjects were shown in Table 2. Influenza virus, parainfluenza virus, respiratory syncytial virus, rhinovirus, and adenovirus were identified, among which influenza virus was the most common virus $(n=16,9.94 \%)$.

Table 5 Description and comparison of ORRs of clinical symptoms between the IFNa1b group and the control group after 7 days of treatment

\begin{tabular}{lll}
\hline Group & $\mathrm{n}$ & ORR \\
\hline Control group & 80 & $66.66 \pm 36.29$ \\
IFNa1b group & 67 & $77.93 \pm 22.35$ \\
$P$ & & 0.044 \\
\hline
\end{tabular}




\section{A}
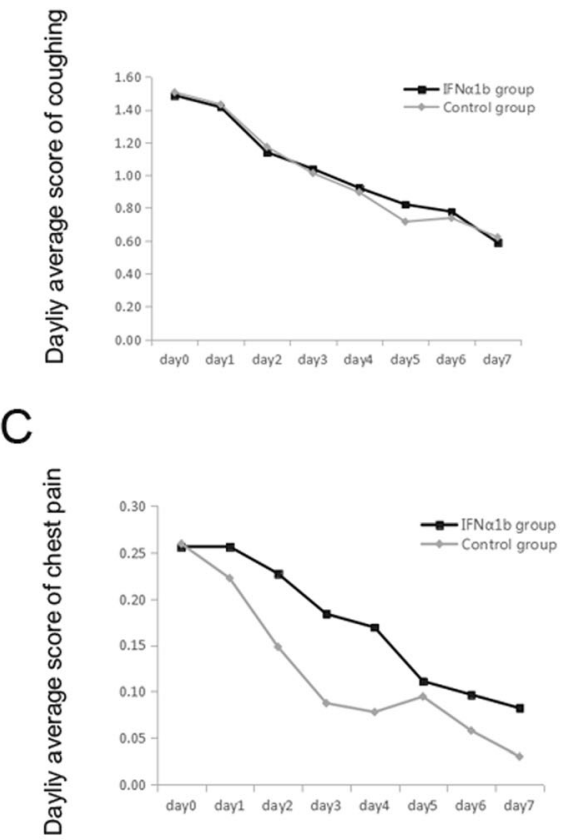

B

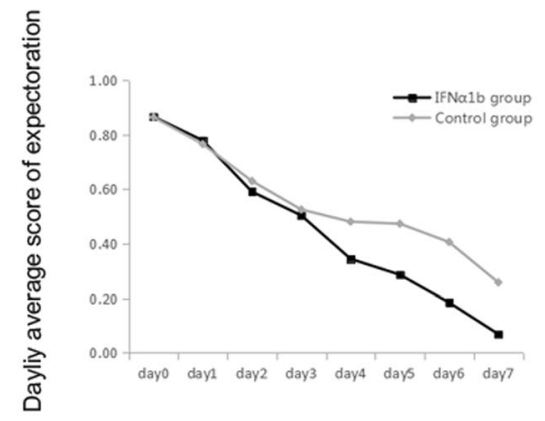

$\mathrm{D}$

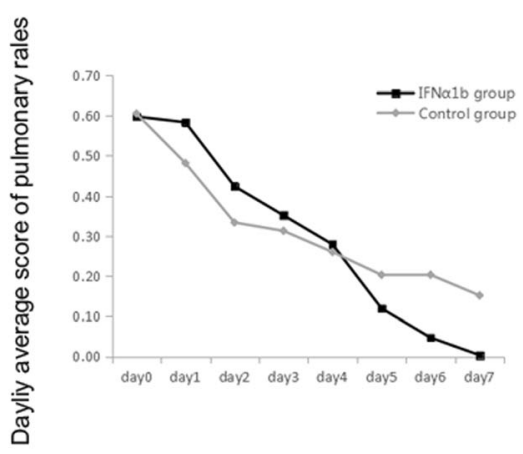

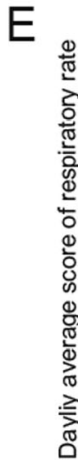

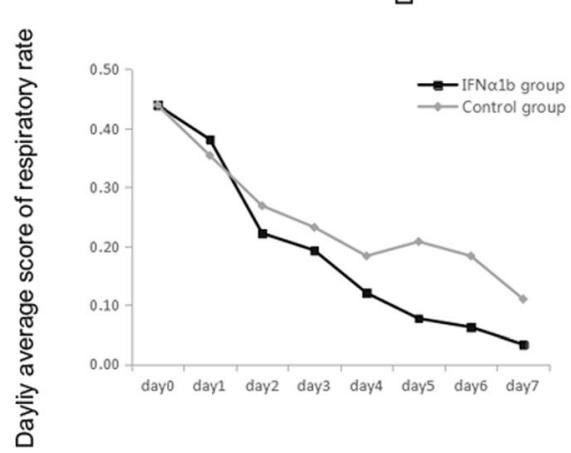

Fig. 2 Daily Scores of Coughing (a), Expectoration (b), Chest Pain (c), Pulmonary Rales (d) and Respiratory Rate (e) in the IFNa1b Group and the Control Group

ORR of clinical symptoms after $\mathbf{7}$ days of treatment

For FAS analysis, the ORR of clinical symptoms was $76.87 \pm 25.15 \%$ in the IFN $\alpha 1$ b group and $65.51 \pm 35.59 \%$ in the control group after 7 days of treatment. For PPS analysis, the ORRs were $77.16 \pm 24.19 \%$ and $66.26 \pm$ $35.65 \%$, respectively. In both FAS and PPS, the ORR was significantly higher in the IFN $\alpha 1 b$ group compared with that in the control group $(P<0.05)$ (Table 3$)$. Covariance analysis showed there was no significant correlation between gender composition and ORRs $(P>0.05)$ (Table 4).

Subjects with a positive influenza virus test were excluded from the original FAS to establish a new FAS. Analysis of the new FAS showed that the ORRs of clinical symptoms after 7 days of treatment were consistent with the original FAS results (Table 5).

\section{Seven-day daily score for each symptom}

During the treatment, the scores of three efficacy measures (expectoration, respiratory rate, and pulmonary rales) decreased rapidly, especially the expectoration and respiratory rate (Fig. 2). On days 2 and 3 of the

Table 6 Response rate of each of the five symptoms before and after Treatment

\begin{tabular}{lllll}
\hline Symptoms & $\begin{array}{l}\text { IFNa1b } \\
\text { Group }\end{array}$ & $\begin{array}{l}\text { Control } \\
\text { Group }\end{array}$ & W & P \\
\hline Coughing & $0.61 \pm 0.40$ & $0.52 \pm 0.40$ & 3706.5 & 0.156 \\
Expectoration & $0.70 \pm 0.44$ & $0.53 \pm 0.49$ & 3897.5 & 0.024 \\
Chest pain & $0.16 \pm 0.37$ & $0.20 \pm 0.40$ & 3182 & 0.535 \\
Pulmonary rales & $0.49 \pm 0.49$ & $0.34 \pm 0.46$ & 3799.5 & 0.042 \\
Respiratory rate & $0.43 \pm 0.50$ & $0.32 \pm 0.47$ & 3677.5 & 0.141 \\
\hline
\end{tabular}


Table 7 Readmissions within 90 Days of Discharge

\begin{tabular}{|c|c|c|c|c|}
\hline & & FAS & & PPS \\
\hline Item & IFN a1b Group & Control Group & IFN a1b Group & Control Group \\
\hline Readmission within 90 days of discharge & $5(6.6 \%)$ & $4(4.6 \%)$ & $5(7.2 \%)$ & $4(4.9 \%)$ \\
\hline No readmission within 90 days of discharge & $71(93.4 \%)$ & $83(95.4 \%)$ & $64(92.8 \%)$ & $78(95.1 \%)$ \\
\hline Total (Missing) & $76(0)$ & $87(0)$ & $69(0)$ & $82(0)$ \\
\hline Statistics & \multicolumn{2}{|c|}{ Fisher's exact probability test } & \multicolumn{2}{|c|}{ Fisher's exact probability test } \\
\hline$P$ & \multicolumn{2}{|l|}{0.735} & \multicolumn{2}{|l|}{0.733} \\
\hline
\end{tabular}

treatment, the IFNa1b group showed the most significant improvement in expectoration and respiratory rate. On day 4 , the IFN $\alpha 1$ b group showed the most significant improvement in pulmonary rales. At the end of treatment, the ORRs of expectoration, respiratory rate, and pulmonary rales remained higher in the IFN $\alpha 1 b$ group than that in the control group.

\section{Response rate of each of the five symptoms before and after treatment}

The response rates of expectoration and pulmonary rales were significantly higher in the IFN $\alpha 1 b$ group than that in the control group $(P<0.05)$ (Table 6$)$. No significant differences of other three symptoms, including coughing, chest pain, and respiratory rate, were observed between the two groups $(P>0.05)$.

Survival rate and readmission within 90 days of discharge Phone follow-ups showed no deaths within 90 days of discharge. Five subjects in the IFN $\alpha 1 b$ group and four subjects in the control group were readmitted into a general ward (non-ICU) within 90 days of discharge due to complaints other than noninfluenza viral pneumonia. Fisher's exact probability test showed no significant between-group difference $(P>0.05)$ for both the FAS and PPS (Table 7).

\section{Antibiotic use}

The rate of antibiotic use was $93.42 \%$ in the IFNa1b group and $90.80 \%$ in the control group $(P>0.05)$ (Table 8). The duration of antibiotic use was $7.84 \pm 3.50$ days in the IFN $11 \mathrm{~b}$ group and $7.99 \pm 3.78$ days in the control group $(P>0.05)$ (Table 9$)$. A quantitative virus test was performed before treatment, on days 3 and 7 of treatment in the IFN $\alpha 1 b$ group. The virus nucleic acid load was significantly decreased on day 7 of treatment relative to that before treatment.

\section{Safety evaluation}

No significant differences of the vital signs (pulse, blood pressure, body temperature, respiratory rate) of the 164 subjects were observed between the two groups $(P>$ 0.05). Physical examinations, including examinations of the skin and mucous membranes, lymph nodes, head and neck, chest, abdomen, spine, musculoskeletal system, and nervous system, revealed no clinically significant abnormal findings. In urine analysis, stool tests, electrocardiography, and blood oxygen saturation level measurements, few subjects showed clinically significant abnormalities, and no significant between-group differences were found $(P>0.05)$. At the end of the treatment, the frequency of abnormal blood and biochemical tests was 176 cases in the IFNa1b group and 158 cases in the control group $(P>0.05)$.

The statistics of adverse events were shown in Table 10. The incidence of adverse events was $6.5 \%$ in the IFN $\alpha 1 b$ group and $3.5 \%$ in the control group. During treatment, two subjects in the IFN $\alpha 1 b$ group had a rash but continued to receive IFN treatment. Their rash disappeared after antiallergic treatment. One subject in the IFN $\alpha 1 b$ group had a sore throat and dry throat, and the symptoms resolved after IFN discontinuation. Two subjects in the IFN $\alpha 1 b$ group and one subject in the control group had a low white blood cell (WBC) count, which was resolved after IFN discontinuation. Moreover, one patient in the control group was pregnant and thus discontinued treatment.

\section{Discussion}

The current study investigated the efficacy and safety of aerosol inhalation of recombinant human interferon $\alpha 1 b$

Table 8 Rate of antibiotic Use in the IFNa1b group and the control group (\%)

\begin{tabular}{|c|c|c|c|c|}
\hline & \multicolumn{2}{|l|}{ FAS } & \multicolumn{2}{|l|}{ PPS } \\
\hline & IFNa1b Group & $\overline{\text { Control Group }}$ & IFNa1b Group & $\overline{\text { Control Group }}$ \\
\hline Use of Item antibiotics & $5(6.6 \%)$ & $8(9.2 \%)$ & $5(7.2 \%)$ & $7(8.5 \%)$ \\
\hline Use of antibiotics & $71(93.4 \%)$ & 79 (90.8\%) & $64(92.8 \%)$ & $75(91.5 \%)$ \\
\hline$P$ & 0.745 & & 1.000 & \\
\hline
\end{tabular}


Table 9 Duration of antibiotic use in the IFNa1b group and the control group

\begin{tabular}{|c|c|c|c|c|}
\hline & FAS & & PPS & \\
\hline Item & IFNa1b Group & $\begin{array}{l}\text { Control } \\
\text { Group }\end{array}$ & IFNa1b Group & $\begin{array}{l}\text { Control } \\
\text { Group }\end{array}$ \\
\hline $\begin{array}{l}\text { n } \\
\text { (Missing) }\end{array}$ & $140(24)$ & $138(22)$ & $122(21)$ & $131(20)$ \\
\hline $\begin{array}{l}\text { Mean } \\
\text { (SD) }\end{array}$ & $7.84(3.50)$ & 7.99 (3.78) & $7.83(3.25)$ & 7.95 (3.83) \\
\hline Median & 8 & 8 & 8 & 8 \\
\hline Q1, Q3 & $5.0,9.3$ & $5.8,10.3$ & $6.0,9.0$ & $5.0,10.5$ \\
\hline Min, Max & 1,16 & 1,16 & 1,16 & 1,16 \\
\hline $95 \% \mathrm{Cl}$ & $7.20,8.49$ & $7.30,8.69$ & $7.19,8.47$ & $7.24,8.67$ \\
\hline Statistics & $\begin{array}{l}\text { Wilcoxon rank } \\
\text { sum test }\end{array}$ & 6523 & $\begin{array}{l}\text { Wilcoxon rank } \\
\text { sum test }\end{array}$ & 5416 \\
\hline$P$ & 0.688 & & 0.670 & \\
\hline
\end{tabular}

(IFNa1b) injection for noninfluenza viral pneumonia. It was found that aerosol inhalation of recombinant human IFN $\alpha 1 b$ could improve the ORRs of the clinical symptoms with our additional adverse events in noninfluenza viral pneumonia.

This study found that the ORRs of primary efficacy measures, including coughing, expectoration, pulmonary rales, respiratory rate, and chest pain were higher in the IFN $\alpha 1 b$ group than that in the control group, which received routine symptomatic treatment alone, suggesting that aerosol inhalation of recombinant human INF $\alpha 1 b$ effectively improves the overall response rate of the disease. IFN $\alpha$ is a recognized immunomodulatory therapy to suppress viral replication by inhibiting basal transcription processes.

Because of its antiviral effects, IFN $\alpha$ has been used in trials in combination with other antiviral agents to prevent and treat emerging and reemerging virus infections for which no approved drugs are available [15-18]. However, results from these trials have yielded inconsistent results. In addition, other studies indicated that IFN $\alpha$ has pathogenic effects during acute and chronic infections [19-23]. Together, these findings suggest that the relationship between virus replication and or related pathogenesis and the kinetics of IFN expression, whether endogenous or after exogenous administration, contributed to the variability of outcomes. IFN $\alpha$ therapy has been used to treat patients with severe respiratory disease caused by CoVs, with similarly inconsistent outcomes [24]. In particular, IFN $\alpha$ treatment of patients with MERS failed to improve survival [15, 25, 26]. For example, in one study, IFN treatment prolonged survival when assessed at 14 days, but not at 28 days [15]. Previous studies have demonstrated a critical role for MDA5 in sensing CoV RNA and thereby initiating the IFN response [27]. The majority of these studies used macrophages infected with a murine $\mathrm{CoV}$, mouse hepatitis virus, which is macrophage tropic $[28,29]$. Since human CoVs predominantly infect airway and alveolar epithelial cells and PRR expression is cell-type specific, we examined the PRRs necessary for IFN production specifically in airway and alveolar epithelial cells using mice transduced with Ad5-hDPP4 and then infected with the human EMC/2012 strain of MERS-CoV. Ad5 predominantly infects epithelial cells and not myeloid cells [30]. Although there was no significant difference of chest pain between the two groups. It could still be found that in early 4 days of the treatment, the average score of chest pain seemed to be lower than IFN $\alpha 1 b$ group. It was reported that the treatment of IFN $1 \mathrm{1b}$ could lead to some adverse events, including pulmonary effusion cardiac insufficiency [31]. Therefore, the mechanism and reason of the early chest pain still needed to be further investigated.

Prophylactic or early therapeutic administration of IFNs during MERS-CoV infection in rhesus macaques provided significant protection [32]. However, studies in humans failed to conclusively establish the beneficial effects of rIFN therapy $[25,26,33]$, possibly because of delayed administration relative to peak virus titers. In the early stage of treatment (days 2 to 3 ), expectoration, respiratory rate, and pulmonary rales were improved. Virus replication occurs in the early stage, therefore,

Table 10 Adverse events during the study

\begin{tabular}{|c|c|c|c|c|c|c|c|}
\hline & & Rash & $\begin{array}{l}\text { Sore Throat, Dry } \\
\text { Throat }\end{array}$ & Low WBC & $\begin{array}{l}\text { Elevated } \\
\text { transaminase }\end{array}$ & $\begin{array}{l}\text { Cessation of menstruation } \\
\text { (Pregnancy) }\end{array}$ & Total \\
\hline \multirow{3}{*}{$\begin{array}{l}\text { Control group ( } n \\
=87)\end{array}$} & $n$ & 0 & 0 & 2 & 0 & 1 & 3 \\
\hline & Severity & - & - & Moderate & - & Severe & \\
\hline & $\begin{array}{l}\text { Relation to the } \\
\text { investigational drug }\end{array}$ & - & - & Unrelated & - & Unrelated & \\
\hline \multirow{3}{*}{$\begin{array}{l}\text { IFNa1b group ( } n \\
=77)\end{array}$} & $n$ & 2 & 1 & 1 & 1 & 0 & 5 \\
\hline & Severity & Mild & Mild & Mild & Moderate & - & \\
\hline & $\begin{array}{l}\text { Relation to the } \\
\text { investigational drug }\end{array}$ & Possible & Possible & Unrelated & Unrelated & - & \\
\hline
\end{tabular}


early treatment may better inhibit virus replication. This study shows that IFN is more effective in patients diagnosed in the early stage, indicating that early treatment is advantageous for disease control and remission, although late treatment is also effective.

When used in the systemic therapy, IFNs are mostly administered by an intramuscular injection. The most frequent adverse effects are flu-like symptoms, especially increased body temperature. In current study, no significant difference of the adverse events was observed between the IFN $1 \mathrm{lb}$ group and the control group, suggesting that aerosol inhalation of recombinant human IFN $1 \mathrm{~b}$ injection was safe and well tolerated.

There were also some limitations in this study. First the analysis of viral pathogens could be uncertain, and not all cases have positive pathogen results. Second, the specimen was collected from the upper respiratory tract, which might not be the same pathogen as the lower respiratory tract.

\section{Conclusion}

In conclusion, aerosol inhalation of recombinant human IFN $1 \mathrm{lb}$ combined with routine treatment is safe and well tolerated in the treatment of noninfluenza viral pneumonia. It significantly improves the ORRs of clinical symptoms and accelerates recovery compared with routine treatment.

\section{Acknowledgements}

N/A

\section{Ethical approval and consent to participate}

This is a multicenter, randomized, double-blind, placebo-controlled trial, which was approved by the Ethics Committee of Beijing Ditan Hospital Capital Medical University. Each subject was informed of the purpose of the study and potential benefits and risks and signed an informed consent before the study.

\section{Conflict of interest}

The authors declare that they have no competing interest.

\section{Authors' contributions}

Rongmeng Jiang and Xingwang Li carried out the integrity of the entire studyand manuscript review; Rongmeng Jiang, Bing Han, Meihua Song and Bing Xue were involved in the study concepts and study design; Rongmeng Jiang focused on the definition of intellectual content; Bing Han, Meihua Song, Bing Xue, Yongxiang Zhang, Jin Chen, Jianhua Liu, Qingrong Nie, Xiuhong Jin, Weian Guo, Zuoging Zhang, Jie Zhang, Jiandong Li were dedicated to the literature research and experimental studies; Rongmeng Jiang, Bing Han, Meihua Song, Bing Xue, Yongxiang Zhang, Yanyan Ding, Jin Chen, Jing Zhu, Jianhua Liu, Qingrong Nie, Xuefeng Han, Xiuhong Jin, Xiaoyin Shan, Weian Guo, Erming Zhang, Zuoqing Zhang, Changhong Zhang, Jie Zhang, Baozeng Wang, Shuwen Dong, Jiandong Li, Xiaoguang Li and Xingwang Li carried out the clinical studies; Rongmeng Jiang, Bing Han, Meihua Song, Bing Xue were involved in the data acquisition; Rongmeng Jiang handled the data analysis, statistical analysis, manuscript preparation and manuscript editing. All authors have read and approved this article.

\section{Funding}

This study was supported by the Beijing science and technology project (topic number: D151100002115002): New treatment methods for viral pneumonia without influenza.

\section{Availability of data and materials}

N/A

\section{Consent for publication}

N/A

\section{Author details}

${ }^{1}$ Department of Infectious Disease, Beijing Ditan Hospital, Capital Medical University, No. 8 East Jingshun Street, Chaoyang District, Beijing 100015, China. ${ }^{2}$ Department of Respiratory Medicine, Beijing Chuiyangliu Hospital, Beijing 100022, China. ${ }^{3}$ Department of Respiratory Medicine, People's Hospital of Beijing Daxing District, Beijing 102600, China. ${ }^{4}$ Department of Respiratory Medicine, Fuxing Hospital, Capital Medical University, Beijing 100038, China. ${ }^{5}$ Department of Respiratory Medicine, Beijing Huairou District Hospital, Beijing 101400, China. ${ }^{6}$ Department of Respiratory Medicine, Liangxiang Hospital of Fangshan District, Beijing 102401, China. ${ }^{7}$ Department of Respiratory Medicine, Beijing Pinggu Hospital, Beijing 101200, China. ${ }^{8}$ Department of Respiratory Medicine, Peking University Shougang Hospital, Beijing 100144, China. ${ }^{9}$ Department of Respiratory Medicine, Beijing Shijingshan Hospital, Beijing 100043, China. ${ }^{10}$ Department of Respiratory Medicine, Beijing Tiantan Hospital, Capital Medical University, Beijing 100070, China. ${ }^{11}$ Department of Infectious Disease, Beijing Tiantan Hospital, Capital Medical University, Beijing 100070, China. ${ }^{12}$ Department of Respiratory Medicine, General Hospital of Beijing Military Region, Beijing 100700, China.

${ }^{13}$ Department of Infectious Disease, Peking University Third Hospital, Beijing 100191, China.

Received: 18 March 2020 Accepted: 4 May 2020

Published online: 14 May 2020

\section{References}

1. Ruuskanen O, Lahti E, Jennings LC, Murdoch DR. Viral pneumonia. Lancet. 2011;377:1264-75.

2. Jain $S$, Self WH, Wunderink RG, Fakhran S, Balk R, Bramley AM, et al. Community-acquired pneumonia requiring hospitalization among U.S. adults. N Engl J Med. 2015;373:415-27.

3. Kochanek KD, Murphy SL, Xu J, Tejada-Vera B. Deaths: final data for 2014. Natl Vital Stat Rep. 2016;65:1-122.

4. File TM Jr, Marrie TJ. Burden of community-acquired pneumonia in north American adults. Postgrad Med. 2010;122:130-41.

5. Burk M, El-Kersh K, Saad M, Wiemken T, Ramirez J, Cavallazzi R. Viral infection in community-acquired pneumonia: a systematic review and meta-analysis. Eur Respir Rev. 2016;25:178-88.

6. de Wilde AH, Raj VS, Oudshoorn D, Bestebroer TM, van Nieuwkoop S, Limpens $R$, et al. MERS-coronavirus replication induces severe in vitro cytopathology and is strongly inhibited by cyclosporin a or interferon-alpha treatment. J Gen Virol. 2013;94:1749-60.

7. Trigg ME, de Alarcon P, Rumelhart S, Holida M, Giller R. Alpha-interferon therapy for lymphoproliferative disorders developing in two children following bone marrow transplants. J Biol Response Mod. 1989;8:603-13.

8. Sakai Y, Ohga S, Tonegawa Y, Takada H, Nakao F, Nakayama H, et al. Interferon-alpha therapy for chronic active Epstein-Barr virus infection: potential effect on the development of T-lymphoproliferative disease. J Pediatr Hematol Oncol. 1998;20:342-6.

9. Bellingan G, Maksimow M, Howell DC, Stotz M, Beale R, Beatty M, et al. The effect of intravenous interferon-beta-1a (FP-1201) on lung CD73 expression and on acute respiratory distress syndrome mortality: an open-label study. Lancet Respir Med. 2014;2:98-107.

10. de Weerd NA, Nguyen T. The interferons and their receptors--distribution and regulation. Immunol Cell Biol. 2012;90:483-91.

11. Samuel CE. Antiviral actions of interferons. Clin Microbiol Rev. 2001;14:778809 table of contents.

12. Liu JF, Liu JJ, Chu LP, Wang DZ, Jia YU, Liu JY. Biodistribution and metabolic pathway of interferon- $a 1 b$ administered by aerosol inhalation in rabbits. Herald of Medicine. 2013.

13. Komatsu H, Inui A, Fujisawa T. Pediatric hepatitis B treatment. Ann Trans Med. 2017;5:37.

14. Kelly DA, Haber B, Gonzalez-Peralta RP, Murray KF, Jonas MM, Molleston JP, et al. Durability of sustained response shown in paediatric patients with chronic hepatitis $C$ who were treated with interferon alfa-2b plus ribavirin. J Viral Hepat. 2012;19:263-70. 
15. Omrani AS, Saad MM, Baig K, Bahloul A, Abdul-Matin M, Alaidaroos AY, et al. Ribavirin and interferon alfa-2a for severe Middle East respiratory syndrome coronavirus infection: a retrospective cohort study. Lancet Infect Dis. 2014; 14:1090-5.

16. Kim UJ, Won EJ, Kee SJ, Jung SI, Jang HC. Combination therapy with lopinavir/ritonavir, ribavirin and interferon-alpha for Middle East respiratory syndrome. Antivir Ther. 2016;21:455-9.

17. Loutfy MR, Blatt LM, Siminovitch KA, Ward S, Wolff B, Lho H, et al. Interferon alfacon-1 plus corticosteroids in severe acute respiratory syndrome: a preliminary study. JAMA. 2003;290:3222-8.

18. Gao L, Yu S, Chen Q, Duan Z, Zhou J, Mao C, et al. A randomized controlled trial of low-dose recombinant human interferons alpha-2b nasal spray to prevent acute viral respiratory infections in military recruits. Vaccine. 2010; 28:4445-51.

19. Channappanavar R, Fehr AR, Vijay R, Mack M, Zhao J, Meyerholz DK, et al. Dysregulated type I interferon and inflammatory monocyte-macrophage responses cause lethal pneumonia in SARS-CoV-infected mice. Cell Host Microbe. 2016;19:181-93.

20. Davidson S, Crotta S, McCabe TM, Wack A. Pathogenic potential of interferon alphabeta in acute influenza infection. Nat Commun. 2014;5:3864.

21. Davidson S, Maini MK, Wack A. Disease-promoting effects of type I interferons in viral, bacterial, and coinfections. J Interf Cytokine Res. 2015;35: 252-64

22. Wilson EB, Yamada DH, Elsaesser H, Herskovitz J, Deng J, Cheng G, et al. Blockade of chronic type I interferon signaling to control persistent LCMV infection. Science. 2013;340:202-7.

23. Teijaro JR, Ng C, Lee AM, Sullivan BM, Sheehan KC, Welch M, et al. Persistent LCMV infection is controlled by blockade of type I interferon signaling. Science. 2013;340:207-11.

24. Stockman LJ, Bellamy R, Garner P. SARS: systematic review of treatment effects. PLoS Med. 2006;3:e343.

25. Shalhoub S, Farahat F, Al-Jiffri A, Simhairi R, Shamma O, Siddiqi N, et al. IFNalpha2a or IFN-beta1a in combination with ribavirin to treat Middle East respiratory syndrome coronavirus pneumonia: a retrospective study. J Antimicrob Chemother. 2015;70:2129-32.

26. Al-Tawfiq JA, Momattin H, Dib J, Memish ZA. Ribavirin and interferon therapy in patients infected with the Middle East respiratory syndrome coronavirus: an observational study. Int J Infect Dis. 2014;20:42-6.

27. Roth-Cross JK, Bender SJ, Weiss SR. Murine coronavirus mouse hepatitis virus is recognized by MDA5 and induces type I interferon in brain macrophages/microglia. J Virol. 2008;82:9829-38.

28. Warwick BA. Mouse macrophages as host cells for the mouse hepatitis virus and the genetic basis of their susceptibility. Proc Natl Acad Sci U S A. 1960; 46:1065-75.

29. Kantoch M, Warwick A, Bang FB. The cellular nature of genetic susceptibility to a virus. J Exp Med. 1963;117:781-98.

30. Kaner RJ, Worgall S, Leopold PL, Stolze E, Milano E, Hidaka C, et al. Modification of the genetic program of human alveolar macrophages by adenovirus vectors in vitro is feasible but inefficient, limited in part by the low level of expression of the coxsackie/adenovirus receptor. Am J Respir Cell Mol Biol. 1999;20:361-70.

31. Mitsui H, Komine M, Shirai A, Kanda N, Asahina A, Okochi H, et al. Chronic active $E B$ virus infection complicated with lgG3 subclass deficiency: an adult case treated with intravenous immunoglobulin and IFN-alpha. Acta Derm Venereol. 2003:83:31-5.

32. Falzarano D, de Wit E, Rasmussen AL, Feldmann F, Okumura A, Scott DP, et al. Treatment with interferon-alpha2b and ribavirin improves outcome in MERS-CoV-infected rhesus macaques. Nat Med. 2013;19:1313-7.

33. Khalid M, Al Rabiah F, Khan B, Al Mobeireek A, Butt TS, Al ME. Ribavirin and interferon-alpha2b as primary and preventive treatment for Middle East respiratory syndrome coronavirus: a preliminary report of two cases. Antivir Ther. 2015;20:87-91.

\section{Publisher's Note}

Springer Nature remains neutral with regard to jurisdictional claims in published maps and institutional affiliations.

\section{Ready to submit your research? Choose BMC and benefit from}

- fast, convenient online submission

- thorough peer review by experienced researchers in your field

- rapid publication on acceptance

- support for research data, including large and complex data types

- gold Open Access which fosters wider collaboration and increased citations

- maximum visibility for your research: over $100 \mathrm{M}$ website views per year

At BMC, research is always in progress.

Learn more biomedcentral.com/submissions 